\title{
9. The Destructive Nadati Earthquake of 1751, with Special Reference to the Seismic Activity of the Itoigawa-Suntô Line.
}

\author{
By Akitune IMAMURA, M. I. A. \\ (Comm. April 12, 1947.)
}

The Nadati earthquake of 1751 , the latest of destructive shocks ever happened in the western part of Etigo Province, is so well recorded that it did not give so much inconvenience in investigating its true nature. The study is important not only in itself but also from the point of view that it would bring much light upon the mutual relations between telluric disturbances exhibited in the surrounding region during the historic times.

The earthquakes took place at about $2 \mathrm{~h}$ on May 21 in the drainage area of the Nadati and the Kuwatori Rivers, the mountainous district mostly Tertiary in formation and lying on the west of the city of Takata. According to the official report made by Takata Clan, then the ruler of the greater portion of the seismic area, houses demolished numbered 6088 and people killed 1128. The total loss of lives should have exceeded 2000 .

It would be worth mentioning that on the day preceding the earthquake, there happened certain events which may be regarded as indications of the fact that there the accumulation of seismogenic stress was approaching its final crisis. It is said that a number of crowds of crow flew away in an unusual manner towards the east over the sky of Takata. That well-water became turbid was noticed by a clansman named Simidu who carefully examined the matter first at Goti, about $6 \mathrm{~km}$. north of Takata, and then at Takata. Further. the so-called phenomenon of seismic luminosity is said to have been exhibited in the district. According to Tatibana-Nankei, a famous traveller, who visited the place 37 years later than the eventful day, the fishermen of Nadati village were fishing in that evening on the sea $30-40 \mathrm{~km}$. off the coast, when they discovered towards their native village an unusual glow such that they mistoock it as the village was on conflagration; every craft hastened homewards but they found nothing like that even in villages other than their own. It was after an hour or two when a tremendous landslide occurred simultaneously with the destructive earthquake: the north-eastern half of the village was buried completely under the debris with its whole inhabitants numbering as much as 800 , with the exception of a single woman who was once thrown into the sea but miraculously saved in virtue of a floating wood.

The above-mentioned landslide started from the Nadati fault, socalled by the late Dr. N. Yamasaki, who investigated, amongst others, the matter early in the beginning of his scientific carrier ${ }^{1)}$. He,

1) Yamasaki: Rep. Earthq. Inv. Comm., 8 (1896), 23. 


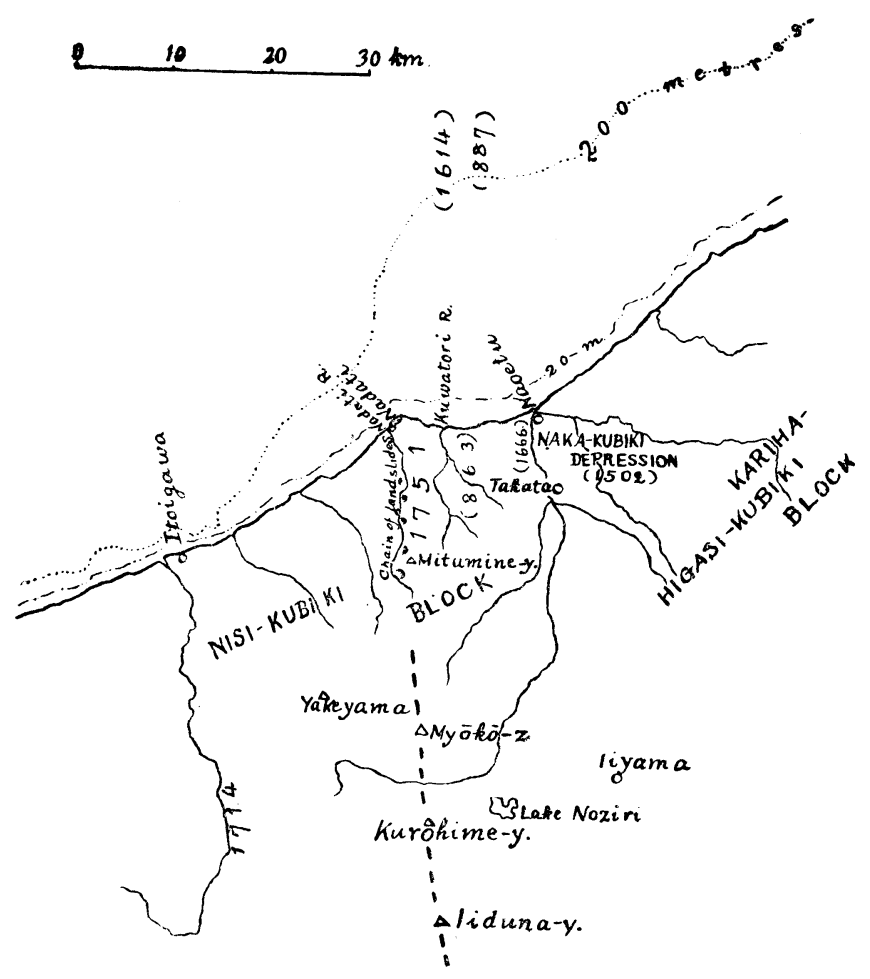

Fig. 1.

however, does not give the whole track of the fault, whereas I am in an opinion that it ran southwards as far as the foot of Mt. Mitumine along the whole course of the Nadati River. The view is based on the fact that there occurred, as in the case of the Kowakubi earthquake of 1914, a chain of landslides on the said line as, for example, those in the villages of Ikeda, Hiraya, Otazima, and Kamota, the farthest, though unrecorded but assumable as such from its present landscape, being situated at a distance of about $18 \mathrm{~km}$. from Nadati. It would also be noteworthy that the line corresponds to the northern extension of a weak zone passing throngh volcanoes Iiduna, Kurohime, and Myôkô.

Again, the fault might possibly have extended farther northwards under the sea. seeing that topographic feature similar to that manifested on land is traceable further towards the north as is evident from the distribution of isobathymetric lines.

Let us now examine change in land-level undergone in the district during a few decades of recent years. There are two lines of precise levels available for the present purpose, one of which links Wazima with Sibata via Itoigawa, Naoetu, and Nigata, and the other, branching from the former at Itoigawa, links it with Matumoto via Oomati. The latter line was particularly useful for working out the topographic change associated with the Oomati earthquake of 1918: besides 
it gave something suggestive in revealing the change associated with the Oomatigumi earthquake of 1714 . What we need at present, how: ever, is the topographic change which can be worked out from the result of survey relating to the other line. Yamasaki took the matter in hand as the subject of his study, his memorable paper entitled "Active tilting of land blocks" having been the outcome". Here he gives two contiguous land blocks, one on the west the Nisikubiki block and the other on the east the Kariha-Higasikubiki block, as those which were undergoing westward tiltings in a chronic manner in the period of 33 years ending in 1927. Although his reasoning is quite correct, there are a few points to be supplemented. Since the line of precise levels he availed himself did not include the section to the west of Itoigawa, the western boundary of the Nisikubiki block was not clearly shown in his illustration, notwithstanding a very sharp discontinuity in land-level was present at a point about $8 \mathrm{~km}$. west of Itoigawa between B.-M. Nos. 2932 and 2933. ${ }^{2}$ The said chronic tilt of this block thus comes out as a value of as much as $0.7 \times 10^{-7}$ par annum. Again, change in height of each bench-mark as adopted by him was merely a relative value, so that to reduce the absolute value from it certain constant must be added to it. There is ground in assuming that among the bench-marks contained in the present levelling line, that at Sibata remained almost unmoved during the period concerned; in taking this mark as the standard of reference, the constant required comes out as $+68 \mathrm{~mm}$. It is so much so that the said blocks underwent in a chronic manner tilts assosiated, on the contrary to Yamasaki's assumption, with slight upheavals particularly on their eastern halves.

It may thus be said that the Nadati earthquake of 1751 originated in the Nisikubiki block with its worst-shaken area on the eastern half of the block. Consequently, it would not be so absurd to assume that the acute land deformation as associated with the earthquake occurred in a mode similar to that of the chronic deformation, that is to say, with an upheaval associated with westward tilt at that portion of the land blockl ying between the Nadati fault and the eastern boundary of the block.

It will now be seen that the result of study so far mentioned would give much convenience in locating the origins of past large earthquakes that took place in the surrounding region prior to the Oomatigumi earthquake of 1714 . They are as follows:

The Takata earthquake of 1614. The littoral with the city of Takata as its civic centre was devastated by means of bad shakings and tidal waves with the result of a loss of many lives. The earthquake might have originated off the coast of Takata presumably with the epifocal zone arranged en échelon with those of the 1714 and 1751 earthquakes.

1) Yamasaki: Proc., 4 (1928), 60.

2) See Imamura: Publ. Earthq. Inv. Comm., 9o (1930), Table IV. 
The Takata earthquake of 1666. The present earthquake was quite local; even chronicles extant in Aidu do not record it. The origin is likely to have been near the city of Takata. the havoc wrought having been almost restricted to the city, where about 1500 lives were lost. This claims in nowise extreme severity in shaking, the so-called snow-city having been on that occasion covered with snow 4.5 metres deep, so that, under the condition, even well-constructed houses would have been too weak against the seismic intensity as high as one-fifth of gravity, or casualty par fallen house should have been much larger than in any other cases.

The Kô earthquake of 1502. There is only a single record dealing with the present earthquake. The author of the record was then staying at Kō (now Naoetu), where, it is told, a number of houses were destroyed with many casualties. The shock might possibly have emerged somewhere from the Nakakubiki depression.

The destructive Etigo-Etty $\hat{u}$ earthquake of 863. The area shaken worst, and landslides accompanied by the shock, together with an event that, it is told, a few islets near Naoetu disappeared with the earthquake, suggest that the present earthquake was similar in its essential characteristics to the Nadati earthquake of 1751 .

The Sinano earthquake of 841 and the Etigo earthquake of 887. Since these shocks took place contemporaneously with the abovementioned Etigo-Ettyû earthquake and the large Idu earthquake of 841, and also with the energetic Huzi eruption of 864, it would not be so absurd in assigning them as the births of the Itoigawa-Suntō line. The Etigo earthquake might be located in the same way as the 1614 earthquake, seeing that it was also accompanied by tidal waves. As to the Sinano earthquake, it may be located on the line somewhere between Oomatigumi and Matumoto-daira.

From what have been so far mentioned, it may be concluded that the dominant activity of the Itoigawa-Sunto line was manifested in two different periods, viz., the earlier in the period covering 47 years from 841 to 887 , and the later in that covering 138 years from 1614 to 1751 . It would be noteworthy that Volcano Huzi, which may be regarded as situated on the said line, made extraordinary energetic eruptions in the above-mentioned periods. 